J. Lake Sci.(湖泊科学), 2016, 28(3): 545-553

DOI 10. $18307 / 2016.0310$

(c) 2016 by Journal of Lake Sciences

\title{
湖北梁子湖近百年来环境演变历史及驱动因素分析”
}

\author{
张清慧, 董旭辉**,羊向东 \\ (中国科学院南京地理与湖泊研究所湖泊与环境国家重点实验室,南京 210008)
}

\begin{abstract}
摘 要: 湖泊生态系统的修复必须建立在历史生态环境演化过程与驱动机制认识的基础之上. 针对草型湖泊演化历史研 究相对不足的现状, 以长江中游典型草型湖泊梁子湖为研究对象, 结合 ${ }^{210} \mathrm{~Pb}$ 和 ${ }^{137} \mathrm{Cs}$ 年代测试, 通过对沉积柱高分辨率的 多指标分析 (硅藻、元素地球化学和粒度) 以及流域历史资料重建近百年来梁子湖生态环境的演化过程, 并在此基础上利 用元余分析定量区分影响该湖泊生态环境演化的关键驱动因子. 结果显示, 沉积物总磷和重金属元素 $\mathrm{Cu}$ 是影响该湖泊 生态环境演化的 2 个显著变量, 它们分别单独解释硅藻组合的 $12.7 \%$ 和 $8.5 \%$ 变率. 这表明近百年来人类活动引起的营 养输人对梁子湖生态环境演化起关键性作用,而重金属污染也是影响梁子湖环境演变的重要因子. 本研究结果可以为梁 子湖及长江中下游其他类似湖泊的环境治理提供科学依据.
\end{abstract}

关键词: 梁子湖; 湖泊沉积物; 硅藻;垙余分析;环境演变

\section{Environmental evolution of Lake Liangzi and its driving factors over the past 100 years, Hubei Province}

\section{ZHANG Qinghui, DONG Xuhui ${ }^{* *}$ \& YANG Xiangdong}

( State Key Laboratory of Lake Science and Environment, Nanjing Institute of Geography and Limnology, Chinese Academy of Sciences, Nanjing 210008, P.R.China)

\begin{abstract}
The restoration of lake ecosystems requires a good knowledge on the history in the lakes and the driving mechanism of environmental changes. Aimed at current situation of limited study on past environmental changes of macrophyte-dominated lake, Lake Liangzi, located in the middle reach of the Yangtze River, was selected for historical environment study. High-resolution multi-proxy (i.e. diatom, geochemistry and grain size), ${ }^{210} \mathrm{~Pb} /{ }^{137} \mathrm{Cs}$ dating of a sediment core collected from this lake and documentary data(i.e. population and air temperature) were analyzed to investigate environmental changes during the past one-hundred years. Furthermore, effects of key driver on the evolution of ecological environment were estimated quantitatively using the redundancy analysis. Results showed that total phosphorus and heavy metal element $\mathrm{Cu}$ from the sediments were two significant variables, explaining solely $12.7 \%$ and $8.5 \%$ of the variances in diatom data, respectively. Therefore, anthropogenic nutrient input was the most important factor on the environmental evolution of Lake Liangzi. Meanwhile, heavy metal pollution also imposed an important effect on this lake. The results of this study can provide a baseline of scientific information for environment restoration in the present lake and other similar lakes in the Yangtze floodplain.
\end{abstract}

Keywords: Lake Liangzi ; lake sediment; diatoms; redundancy analysis; environmental change

健康的湖泊生态环境是长江中下游地区可持续发展的重要保障 ${ }^{[1]}$. 近几十年来, 随着气候变暖和强烈 人类活动的影响, 该区浅水湖泊面临着严重的水体富营养化问题, 大多数湖泊已由水生植物茂盛、水质清澈 的以水草为主的草型湖陆续转变为藻华频发、水质浑浊的以浮游藻类为主的藻型湖, 生态环境明显退化 ${ }^{[2]}$. 从湖泊生态系统所能提供的服务功能来看,草型湖泊对于人类社会所需求的资源与环境以及支撑社会经济 活动具有更大的服务价值 ${ }^{[3]}$. 因此, 了解草型湖形成与演化机制, 对该区富营养藻型湖泊的生态修复具有重

* 国家自然科学基金项目 (41102105,41472314,41530753)资助. 2015-06-23 收稿; 2015-09-28 收修改稿. 张清 慧(1990 ),女,博士研究生;E-mail: zqh900317@ 163. com.

** 通信作者;E-mail: xhdong@ niglas.ac.cn. 
要意义, 然而该区相关研究大多以富营养藻型湖泊为研究对象, 而对生态状况尚好的草型湖泊的研究开展 得较少. 湖泊生态系统是长期演化的产物. 为有效地修复和治理湖泊生态环境, 确保湖泊资源可持续地为人 类所用, 需要我们从历史的视角来考察湖泊环境的形成及演化机制, 剖析自然条件和人类活动对湖泊环境 演变的影响力度,进而探寻和确定湖泊生态环境退化和转变的原因.

在浅水湖泊中,较快的沉积速率提供了连续无间断的沉积记录; 成熟的年代学技术为获得可靠的时间 序列提供了依据; 丰富的生物与环境信息为反演生态环境的长期变化提供了重要保证. 结合高分辨率的 ${ }^{210} \mathrm{~Pb} /{ }^{137} \mathrm{Cs}$ 定年技术, 基于沉积物多种理化-生物指标的分析, 能有效地提供历史时期湖泊水环境变化的信 息 ${ }^{[4]}$. 其中, 沉积物生物指标硅藻因生命周期短、对环境变化响应敏感、属种丰富、能较好地保存于湖泊沉积 物中, 是古湖沼学研究使用最多的生物类群 ${ }^{[5]}$. 在长江中下游地区, 基于沉积物硅藻与理化指标, 太白湖、龙 感湖和巢湖等湖泊生态环境演化过程得以重建 ${ }^{[4-7]}$, 为这些湖泊的富营养化治理提供了重要信息.

湖泊生态环境往往同时经受营养、水文和气候等诸多环境因子的影响, 而区分不同环境因子的影响力 度是揭示湖泊生态环境演化机制的关键 ${ }^{[8]}$. 近年来, 随着统计学的发展, 特别是多元统计回归、梯度分析理 论如典型对应分析 (canonical correspondence analysis, CCA)、元余分析 (redundancy analysis, RDA) 等方法的 成熟, 使得定量区分不同环境因子对湖泊生态环境的影响的研究成为可能 ${ }^{[9]}$. 其中 RDA 是一种直接梯度分 析方法, 能从统计学的角度来评价一个或一组变量与另一组多变量数据之间的关系 ${ }^{[10-11]}$. 由于生物群落变 化能反映水体环境变化的综合信息 ${ }^{[12]}$. 因此该类研究大多用硅藻 (对水环境响应非常敏感的生物) 来代表 水环境的演化, 而用其他沉积指标或者流域相关历史资料数据来进行解释 ${ }^{[13]}$. 在长江中下游地区, 董旭辉 等基于 RDA 分析方法, 提取了太白湖能显著解释水环境演化的指标并揭示出影响该湖营养演化的主要驱 动因素 ${ }^{[13]}$; 陈旭等基于 RDA 分析方法, 定量区分巢湖近 50 年来营养、水文和气候对硅藻组合演替的影响, 进而揭示出营养、水文和气候变化共同作用下湖泊生态环境演化过程 ${ }^{[8]}$. 这些研究均基于统计分析, 很好地 揭示了湖泊生态环境演化的驱动因素, 为制定流域湖泊生态修复措施提供参考.

对梁子湖的演化历史,一些研究分别从沉积物氮磷、重金属元素、水生生物遗存和色素、有机质稳定同 位素等方面进行了报道 ${ }^{[14-17]}$, 强调了人类活动在该湖演化历史中的重要性, 但未揭示出具体的环境变化驱 动要素, 也未系统地考虑多沉积指标间的相互作用与影响. 先前笔者所在课题组已基于梁子湖沉积岩芯 ${ }^{210} \mathrm{~Pb} /{ }^{137} \mathrm{Cs}$ 测年和沉积硅藻序列, 对该湖沉积硅藻揭示的历史时期水生植被的信息进行了研究 ${ }^{[18]}$. 考虑到 近百年来相对较高的钻孔分辨率及较多的历史文献资料, 本研究选择硅藻保存性较好的顶部 $49 \mathrm{~cm}$ 沉积岩 芯记录, 结合高分辨率的多指标分析 (硅藻、粒度、地球化学指标等), 探讨过去 100 年来梁子湖生态环境的 演化过程, 以降低单一沉积指标对环境指示的局限性和多解性, 并通过元余分析来提取能显著解释水环境 演化的指标, 定量区分不同环境因子对硅藻组合演替的影响,进而阐述影响该湖环境演化的主要驱动因素.

\section{1 研究区概况}

梁子湖 $\left(30^{\circ} 05^{\prime} \sim 30^{\circ} 18^{\prime} \mathrm{N}, 114^{\circ} 21^{\prime} \sim 114^{\circ} 39^{\prime} \mathrm{E}\right)$ 生态系统完整、物种丰富, 自然属性保持良好, 是目前全 国保护最好的淡水湖之一 ${ }^{[19]}$. 水生植被发育良好, 为典型草型湖泊. 该湖位于长江中游南岸、湖北省东南 部, 地跨武汉市江夏区 (原武昌县) 和鄂州市, 面积 $304.3 \mathrm{~km}^{2}$, 平均水深 $4.16 \mathrm{~m}^{[20]}$. 湖区属北亚热带季风气 候, 年均气温 $16.8^{\circ} \mathrm{C}$, 年降水量 $1263.4 \mathrm{~mm}$. 湖水依赖地表径流和湖面降水补给, 集水面积 $3265 \mathrm{~km}^{2}$, 补给系 数 10.7. 洪涝灾害时有发生, 多年平均水位 $17.81 \mathrm{~m}^{[20]} .1960 \mathrm{~s}$ 前, 该湖为通江敞水湖, 高水位时与保安湖和 鸭儿湖连成一片, 水色明亮, 水质清澈, 生物资源十分丰富 ${ }^{[19]}$. 由于围湖怎殖, 1958 年该湖与鸭儿湖、保安 湖、三山湖完全分开. 1970 年前后, 流域内掀起了围湖圼殖高潮, 至 1972 年梁子湖仅有水面 $334 \mathrm{~km}^{2}$ (围垦前 面积 $\left.454.6 \mathrm{~km}^{2}\right)^{[19]}$. 1972 年以后, 随着柇口新闸和电排泵站的修建, 排水能力提高, 梁子湖的围垦进一步 加剧, 直到 1980 年梁子湖的围旺才得以制止 ${ }^{[19]}$. 目前, 梁子湖营养状态已从贫营养型进人中营养型, 局部已 接近富营养型 ${ }^{[19]}$.

\section{2 研究方法}

\section{1 采样、沉积指标分析}

2011 年在东梁子湖 $\left(30^{\circ} 10^{\prime} \mathrm{N}, 114^{\circ} 37^{\prime} \mathrm{E}\right.$, 水深 $2.7 \mathrm{~m}$ ) 利用重力采样器采集长 $85 \mathrm{~cm}$ 的柱状沉积岩芯. 沉 
积岩芯现场分样, 每个子样品厚度 $1 \mathrm{~cm}$, 样品密封带回实验室后于 $<4^{\circ} \mathrm{C}$ 保存以备分析测试. 本文仅对上部 $49 \mathrm{~cm}$ 沉积柱进行分析. 实验室分析项目包括 ${ }^{210} \mathrm{~Pb} 、{ }^{137} \mathrm{Cs}$ 活度、总磷 (TP)、重金属 (多金属元素间呈现强相 关关系,下文以 $\mathrm{Cu}$ 为代表, 表示人类活动导致的重金属污染)、烧失量 ( LOI)、粒度和硅藻分析. ${ }^{210} \mathrm{~Pb}$ 和 ${ }^{137} \mathrm{Cs}$ 活度采用高纯锗井型探测器 (HPGe GWL-120-15) 测定. TP 和 Cu 用等离子体原子发射光谱仪 (ICP-AES) 测定, 仪器精度控制在重复测量误差小于 $\pm 5 \%$. 烧失量是估算沉积物中有机碳含量有效而便捷的方法, 它是 在马弗炉 $550^{\circ} \mathrm{C}$ 下灼烧 $4 \mathrm{~h}$ 测得 ${ }^{[21]}$. 粒度用 Mastersizer 2000 型激光粒度仪测量, 元素和粒度分析步骤方法详 见参考文献[22]. 硅藻样品采用盐酸和双氧水处理后制片的方法, 种属鉴定参照 Krammer 和 Lange-Bertalot (1986-1991 年) 的分类系统 ${ }^{[23]}$,每个样品的硅藻统计数以 300 粒为基数,属种丰度以百分比表示.

\section{2 流域资料数据}

由于采样点位于东梁子湖鄂州市流域, 因此选择鄂州市人口数据反映流域人口情况, 数据来源于《鄂州 市志》 ${ }^{[24]}$ 和中国经济与社会发展数据库. 选用武汉气温距平来代表流域气温变化,武汉市旱涝等级来代表 流域旱涝变化, 1918-2000 年武汉气温距平和旱涝等级数据分别源自文献 [25-26],2000-2011 年数据均取 自国家气候中心整理公布的中国 160 站逐月平均气候资料进行补充. 为配合沉积指标数据进行数据分析, 对人口数据采用均值内插的方法建立连续的年均数据.

\section{3 数值分析}

梁子湖古湖水总磷浓度的定量重建基于钻孔化石硅藻数据和已经建立的长江中下游地区 49 个现代湖 泊的硅藻-总磷转换函数模型 ${ }^{[27]}$. 在 RDA 分析中选择至少在两个样品中出现且至少在一个样品中含量大于 $1 \%$ 的硅藻属种 (共计 72 个). 以硅藻组合作为响应变量, 所有环境因子 (包括沉积速率、中值粒径、烧失量、 $\mathrm{TP} 、 \mathrm{Cu} 、$ 人口、气温和旱涝等级) 作为解释变量, 基于蒙特卡洛置换检验 $(P<0.01 ; n=499$, 非限制性置换) 逐 步预选篮选出解释硅藻组合演替的显著因子. 为去除显著因子之间共线性的影响, 再对笁选出的所有显著 变量进行冗余分析, 去掉膨胀系数最大的显著因子, 直到所有变量的膨胀系数小于 $5^{[28]}$. 确定显著因子后, 每次选择一个显著因子做解释变量, 余下显著因子做协变量 ( covariable), 进行偏圥余分析 (partial RDA), 计 算每个因子单独作用对硅藻组合演替的解释份额. 蒙特卡洛置换检验 $(P<0.01 ; n=499$, 非限制性置换) 用 于分析解释变量的显著水平. 所有排序分析用 CANOCO 4. 5 软件进行 ${ }^{[1]}$.

\section{3 结果}

\section{1 钻孔年代}

梁子湖钻孔年代结果已发表, 详细结果见参考文献 [ 18]. 考虑到近百年来相对较高的钻孔分辨率及较 多的历史文献资料,本研究选择硅藻保存性较好的顶部 $49 \mathrm{~cm}$ (1919 年)沉积岩芯记录.

\section{2 沉积硅藻组合}

梁子湖钻孔沉积物中共鉴定出硅藻 28 属 170 种, 属种丰富, 包括浮游、附生和底栖类型. 其中, 浮游种 以 Aulacoseira granulata 为主且在钻孔 $11 \mathrm{~cm}$ 以下占绝对优势. A. ambigua 也保持一定含量并与 A. granulata 互为消长关系. 除此之外, 其他浮游硅藻如 A. alpigena, Cyclotella pseudostelligera, C. meneghiniana 等也偶有出 现. 底栖种以 Navicula 和 Nitzschia 的类型以及 Gyrosigma acuminatum 为主. 附生种类总含量很高, 最高达 73\% , 且属种丰富, 包括 Achnanthes minutissima、Fragilaria capucina、Cymbella spp.、Eunotia spp. Gomphonema spp. Epithemia adnata 等. 其中以 A. minutissima、F. capucina 为主要优势附生种, 其它附生种如 Cymbella spp.、Eunotia spp. Gomphonema spp.、E. adnata 等也频繁出现但含量相对较低. 此外, 兼附生浮游的 F. ulna 也常以伴生种出现. 根据硅藻丰度变化可划分为 4 个组合带(图 1), 详细分析结果见参考文献 [18].

在梁子湖沉积柱 170 个硅藻属种中, 有 68 个在长江中下游地区转换函数数据库中出现, 这 68 个属种在 每个样品中的含量均超过 $82 \%$. 结果显示, 整个沉积柱重建水体总磷值 (DI-TP) 相对稳定, 在 $52 \mu \mathrm{g} / \mathrm{L}$ 上下 波动.

\section{3 多指标对比}

为综合分析环境代用指标反映的环境演化信息,综合硅藻、地球物理化学指标、气候水文数据等进行综 合对比分析. 其中硅藻组合中选择两个主要优势属种 A. granulata 和 A. minutissima; 地球物理化学指标包括 


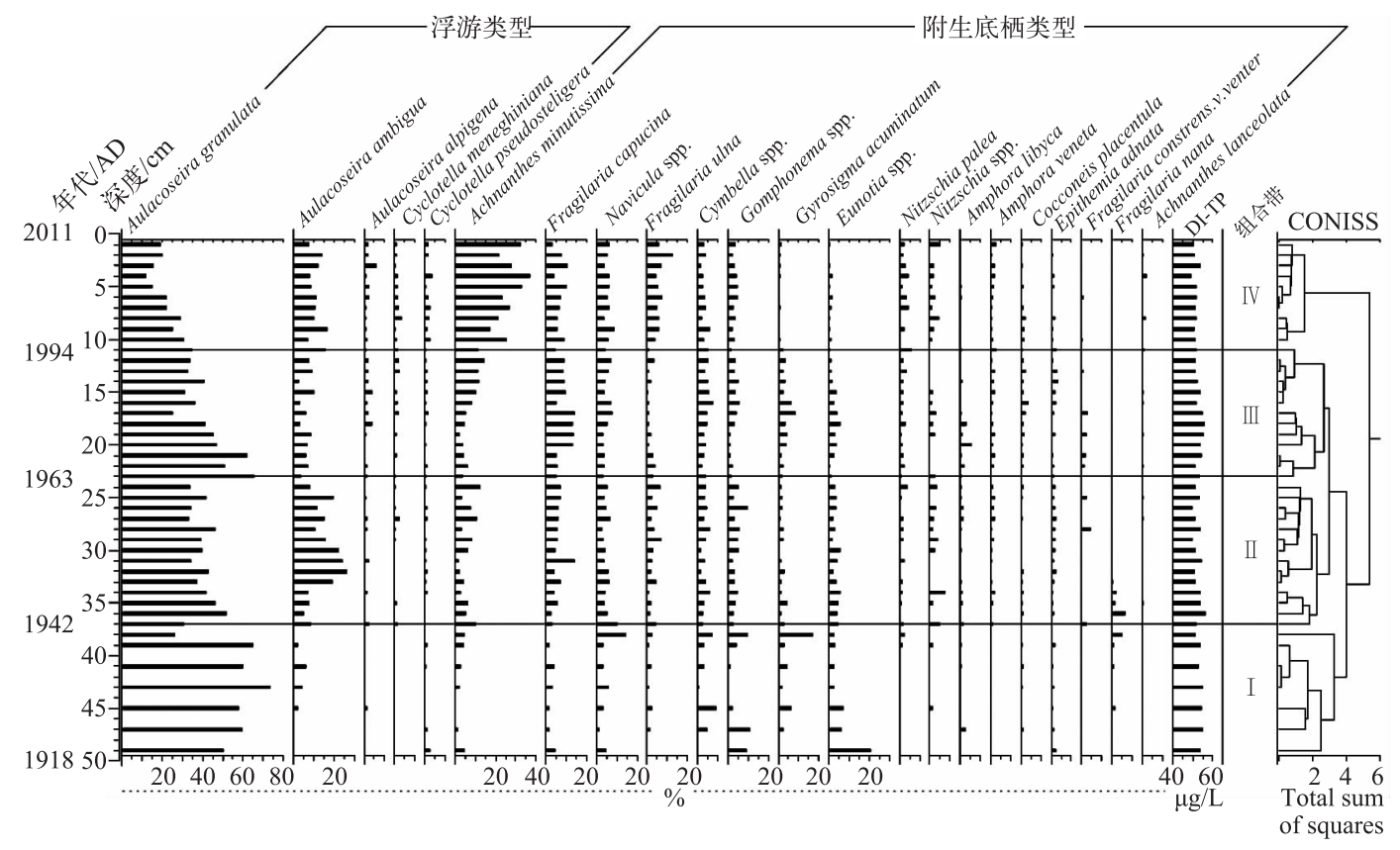

图 1 梁子湖沉积柱主要的硅藻种群演替与硅藻重建水体总磷

Fig. 1 Main diatom species in the sediment core and diatom-inferred total phosphorus in water column of Lake Liangzi

TP、Cu、LOI、沉积速率和中值粒径. 各指标之间具有较好的对应关系. 以硅藻组合图谱的划带为基准, 对多 指标综合分析,分析结果如图 2 所示.

I 带 (49 37 cm; 1918-1942 AD) 这一时期硅藻组合以浮游种 A. granulata 占绝对优势, A. minutissima 只是少量出现. 地球化学指标、LOI 以及粒度在整个沉积柱中均处于较低水平且相对稳定, 仅有小幅变化出 现, 其中 LOI 在 $39 \mathrm{~cm}$ (1940 年) 和 $48 \mathrm{~cm}$ (1920 年)左右出现谷值.

II 带 (37 23 cm; 1942- $1963 \mathrm{AD})$ A. granulata 含量明显减少, 与之同属的 A. ambigua 含量显著增多, $A$. minutissima 含量逐渐增加. TP 含量波动较大并在 $29 \mathrm{~cm}$ (1955 年) 和 $35 \mathrm{~cm}$ (1945 年) 处出现两个凸值, $\mathrm{Cu}$ 自 $27 \mathrm{~cm}$ (1958 年) 处开始增加, LOI 、中值粒径和沉积速率基本稳定.

III带 $(23 \sim 11 \mathrm{~cm}$; 1963-1994 AD) 硅藻组合中 A. granulata 含量总体呈减少趋势, 仅在本带底部有所增 加, 之后又逐渐减少, 与之同属的 A. ambigua 含量显著减少, 而 A. minutissima 含量呈快速增加趋势. 重金属 元素 $\mathrm{Cu}$ 含量仍保持高值, 中值粒径变粗, LOI 和 TP 含量明显增加.

IV 带 (11 0 cm;1994-2011 AD) 硅藻组合发生明显转变, 附生种 A. minutissima 快速增加至剖面最大 值, 成为优势种, 而 A. granulata 含量明显减少, 沉积速率及各地球化学指标均有不同程度的增加并达到剖 面最大值, 中值粒径无明显变化.

近百年来梁子湖流域气温变化具有明显的阶段性, 1918-1942 年为偏暖时段, 1942-1994 年为相对偏 冷阶段, 而 1994 年以来气温明显升高. 流域旱涝灾害频繁, 旱涝事件多发时段出现在 1963 年以后. 流域人 口总数自 1963 年以后呈快速上升趋势.

相关分析结果表明, 以上 10 个因子可分为两组不同的变量:第 1 组包括 A. minutissima、沉积速率、中值 粒径、LOI、TP、Cu、人口和气温, 这 8 个变量两两之间均呈显著正相关, 例如 A. minutissima 和沉积速率之间 呈显著正相关; 第 2 组包括 A. granulata 和旱涝等级, 其中 A. granulata 与第一组变量大多都呈显著负相关, 例如 A. granulata 与重金属元素 $\mathrm{Cu}$ 呈显著负相关,而旱涝等级与其它变量均无显著相关关系 (表 1). 


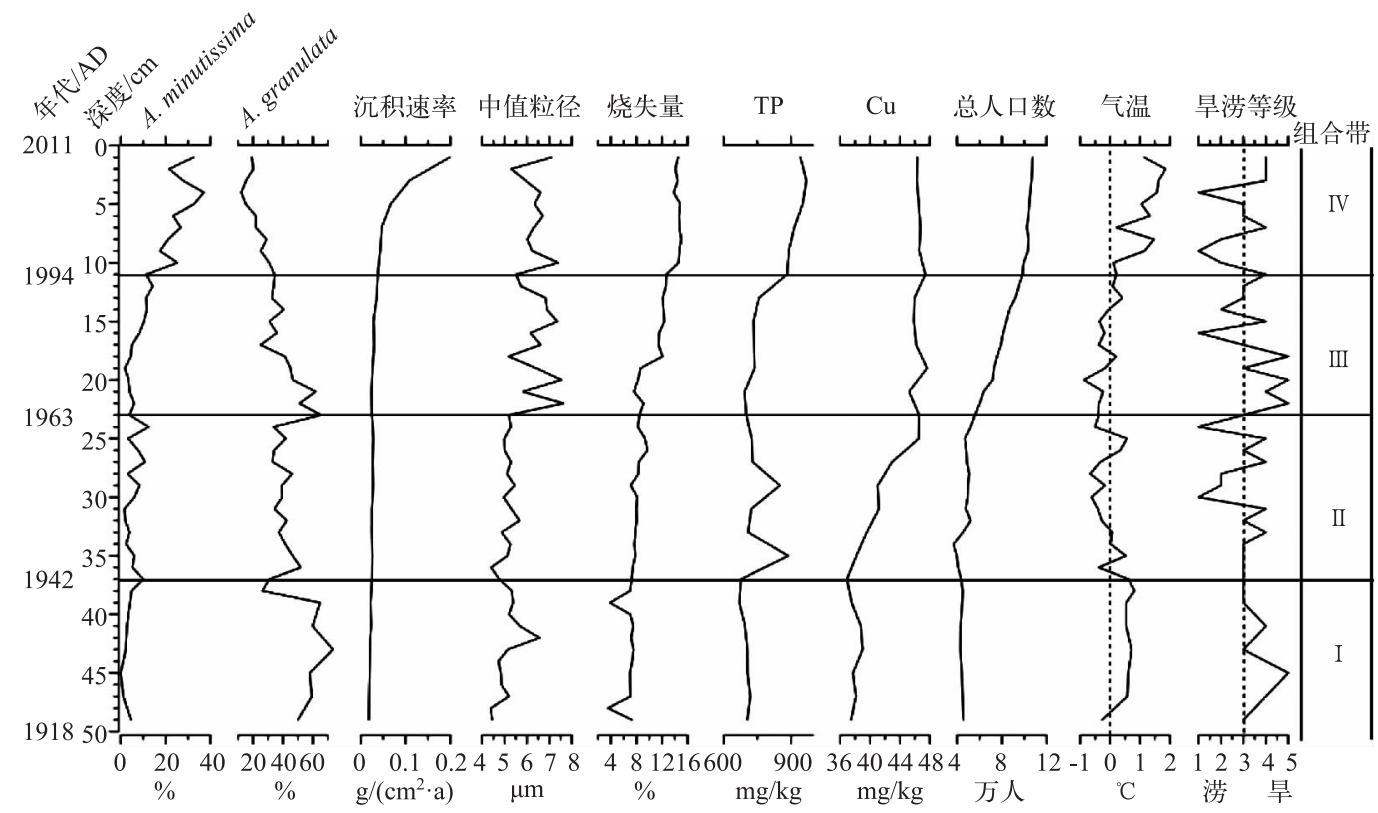

图 2 硅藻优势种、沉积速率、中值粒径、地球化学指标以及梁子湖流域人口、气温与旱涝等级

Fig. 2 Changes of dominant diatom species, sedimentation rate, median grain size, geochemical indicators in the sediment core, and total population, temperature and drought and flood grade in the Lake Liangzi Basin

表 1 多指标 Pearson 相关分析*

Tab.1 Pearson correlation analysis among multiple proxies

\begin{tabular}{ccccccccccc}
\hline & $A c m i$ & Augr & MAR & MD & LOI & TP & Cu & 人口 & 气温 & 旱涝等级 \\
\hline Acmi & & 0.00 & 0.00 & 0.00 & 0.00 & 0.00 & 0.00 & 0.00 & 0.00 & 0.13 \\
Augr & $-0.77^{* *}$ & & 0.00 & 0.02 & 0.00 & 0.00 & 0.00 & 0.00 & 0.00 & 0.16 \\
MAR & $0.73^{* *}$ & $-0.57^{* *}$ & & 0.06 & 0.00 & 0.00 & 0.01 & 0.00 & 0.00 & 0.69 \\
MD & $0.45^{* *}$ & $-0.36^{*}$ & 0.29 & & 0.00 & 0.06 & 0.00 & 0.00 & 0.79 & 0.87 \\
LOI & $0.82^{* *}$ & $-0.74^{* *}$ & $0.60^{* *}$ & $0.56^{* *}$ & & 0.00 & 0.00 & 0.00 & 0.00 & 0.39 \\
TP & $0.84^{* *}$ & $-0.68^{* *}$ & $0.69^{* *}$ & 0.29 & $0.78^{* *}$ & & 0.00 & 0.00 & 0.00 & 0.18 \\
Cu & $0.52^{* *}$ & $-0.48^{* *}$ & $0.37^{*}$ & $0.64^{* *}$ & $0.76^{* *}$ & $0.44^{* *}$ & & 0.00 & 0.53 & 0.68 \\
人口 & $0.82^{* *}$ & $-0.69^{* *}$ & $0.63^{* *}$ & $0.65^{* *}$ & $0.94^{* *}$ & $0.75^{* *}$ & $0.78^{* *}$ & & 0.00 & 0.47 \\
气温 & $0.62^{* *}$ & $-0.43^{* *}$ & $0.61^{* *}$ & 0.04 & $0.50^{* *}$ & $0.60^{* *}$ & 0.10 & $0.49^{* *}$ & & 0.92 \\
旱涝等级 & -0.23 & 0.22 & 0.06 & 0.03 & -0.13 & -0.21 & -0.06 & -0.11 & -0.02 & \\
\hline
\end{tabular}

* Augr 代表 A. granulata;Acmi 代表 A. minutissima; MAR 代表沉积速率; MD 代表中值粒径. 右上角为显著性水平; 左下角 为相关系数. $* *$ 表示显著水平 $P \leqslant 0.01, *$ 表示显著水平 $P \leqslant 0.05$.

\section{4 几余分析}

几余分析结果揭示了硅藻组合变化与环境因子之间的关系,结果显示 $\mathrm{Cu}$ 和 TP 是影响硅藻组合变化的 显著变量 $(P<0.01)$, 这 2 个显著变量前 2 个轴共解释了硅藻数据方差的 $25.2 \%$, 选择第 1 和第 2 排序轴做 穴余分析的双轴图, 记录硅藻组合与环境因子之间的相关关系. 如图 3 所示, 所有沉积样品有规律地分布在 平面图中,组合带 I 到组合带 $\mathrm{IV}$ 样品点大致自左向右由 $\mathrm{TP}$ 和 $\mathrm{Cu}$ 的负方向向正方向转移. 偏先余分析结果 表明, TP 和 $\mathrm{Cu}$ 两个环境因子单独解释率依次为 $12.7 \%$ 和 $8.5 \%$ (表 2). 


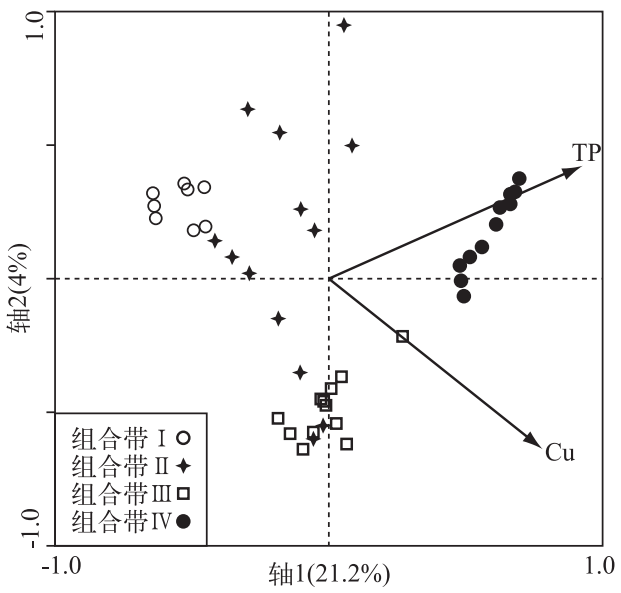

图 3 穴余分析双轴图

Fig. 3 The biplot of redundancy analysis

表 2 偏圥余分析结果和各个变量的显著水平

Tab.2 The results of partial redundancy analyses 响应变量 解释变量 协变量 解释份额\% $P$ 值 $F$ 值

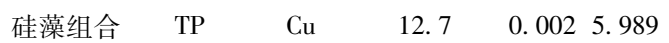
\begin{tabular}{lllll}
$\mathrm{Cu}$ & $\mathrm{TP}$ & 8.5 & 0.002 & 3.814 \\
\hline
\end{tabular}

\section{4 讨论}

\section{1 梁子湖生态环境演化的特征}

影响湖泊沉积的因素众多且较复杂, 对沉积物多 环境指标进行综合分析, 可以消除单一沉积指标对环 境指示的多解性所带来的不确定性, 使其对环境变迁 的解释更为合理和可靠. 基于梁子湖沉积物的多指标 分析包括硅藻、粒度、沉积物总磷、重金属元素等呈现 出基本一致的阶段性变化 (图 2) 且呈显著相关 (表 1), 反映了湖泊生态系统各要素对环境变化过程响应的一 致性. 因此, 梁子湖沉积物较好地记录了过去近百年来 该湖的环境演变过程. 基于此, 结合流域历史资料, 根 据沉积指标中沉积物粒度、营养指标 (TP 和 LOI) 和重 金属元素含量变化以及硅藻组合特征, 对近百年来梁 子湖环境演变的过程进行了重建,叙述如下：

1918-1942 年间, 该湖为通江敞水湖, 水面开阔, 高 水位时与保安湖和鸭儿湖连成一片. 硅藻组合以 $A$. granulata 为优势种, 它是一种硅化程度高、有较高沉降 率且偏好于扰动强烈的水体以保证其悬浮于水柱的属 种 ${ }^{[7]}$. 因此, 此阶段出现的大量 A. granulata 指示了较强 的水体混合和水动力条件. 浅水湖泊的附生硅藻组合 可以指示水生植被覆盖度的变化 ${ }^{[29]}$. 因此本阶段一定 含量的附生硅藻 (如 Gomphonema 和 Eunotia 的种类) 指 示水生植物相对发育, 但含量相对较低反映了当时水生植物发育程度不高, 为水生植物的自然发育阶段. 由于 此阶段水面开阔, 采样点离岸距离大, 以及滨湖湿地植被对陆源颗粒物拦截功能, 使得粗颗粒物质很难到达湖 心, 因此中值粒径较小. 另外, 沉积物中营养指标和重金属元素含量在整个沉积柱中均处于较低水平, 说明当 时流域人类活动干扰较小, 湖泊沉积延续以往的自然演变轨迹. 推测当时该湖水体环境优良, 水动力条件较 强,水生植被自然发育, 湖泊生态系统稳定.

1942-1963 年间, 原先的通江敞水湖泊被人为地改造成了封闭型湖泊, 水动力条件减弱, 水体混合程度 有所降低, 不利于浮游种 A. granulata 发育, 相反, 适宜附生硅藻发育, 各个附生硅藻种类均有不同程度的增 加, 说明当时水生植被有所增加. 沉积指标中除 TP 浓度在 $29 \mathrm{~cm}$ (1955 年) 和 $35 \mathrm{~cm}$ (1945 年) 处出现 2 个峰 值外, 其他营养指标与重金属元素基本保持稳定. TP 出现的这 2 个峰值, 反映了两次营养水平快速升高的 过程, 可能指示了当年较大规模的洪水携带大量的营养盐和泥沙等颗粒物质进人水体, 而且某些颗粒物质 类似于絮凝剂, 能够吸附营养盐并最终沉积在沉积物中 ${ }^{[30]}$, 从而导致沉积物 TP 浓度升高, 这与历史文献记 载中的 1954 年和 1948 年的洪水事件相对应 ${ }^{[31]}$. 推测当时该湖水体环境仍较好, 水动力条件减弱, 水生植被 有所增加, 呈现出良性循环的相对稳定的生态体系.

1963-1994 年间, A. granulata 丰度总体呈逐渐减少的趋势, 表明水动力条件逐渐减弱. 值得注意的是 在 $20 \mathrm{~cm}$ (1972 年) 以下, A. granulata 丰度较上一带是先增加的. 这是由于受洪水的影响, 湖泊水位升高, 水 体浑浊度迅速增加, 因此比较适合 A. granulata 的生长, 这与历史文献记载中的 1962、1964 和 1969 年洪水事 件相对应 ${ }^{[31]}$. 而 1972 年娤口大闸建成后, 排水能力提高, 湖泊水位降低, A. granulata 丰度也随之逐渐减少. 沉积物的粒度增大暗示着人类对湖泊流域的扰动加大, 使得大量未经完全风化的物质进人了湖泊 ${ }^{[32]}$, 因此 本阶段中值粒径的显著增大指示了人类活动的显著增强. 1960s 以来湖区受 “以粮为纲” 的影响, 大面积的围 湖造田、毁林开荒, 以及以 1958 年武汉钢铁公司的投产为代表的现代工业大发展 ${ }^{[31]}$ 的影响下, 沉积物营养 指标和重金属元素含量普遍增加. A. minutissima 等附生硅藻含量快速上升, 表明水生植被快速增加. 1970s 
湖泊围垦和水利工程建设达到高峰期 ${ }^{[31]}$ 以及人类活动的加强所导致的人湖营养盐增加及围怎所导致的湖 泊淤积变浅,这些因素均有利于水生植物的大量生长. 同时水生植物生长发育可以吸收部分营养盐, 对悬浮物 质具有吸附和净化等功能, 能使水体 TP 浓度保持低值. 因此, 本阶段由于人湖营养盐增加, 水体营养水平略有 升高. 同时附生硅藻反映水生植物的大量生长, 有助于水体净化, 硅藻重建水体 TP 浓度始终低于 $60 \mu \mathrm{g} / \mathrm{L}$.

1994-2011 年间, 沉积物 TP 含量明显升高, 生物多样性减少, 生态系统出现一定程度的退化. 平均沉积 速率显著增高 (图 2) 指示了流域人类活动强度的显著增加, 由此引起流域土壤侵蚀速率加快和人湖营养物 质等显著增多, 营养指标和重金属元素均达到剖面最大值. 这一阶段硅藻组合开始发生明显转变, $A$. granulata 丰度持续下降, 附生种 A. minutissima 明显增加, 成为优势种, 但一些附生种如 Eunotia spp. 和 Gyrosigma acuminatum 在此阶段逐渐减少甚至消失. 研究表明沉积附生硅藻记录还可以揭示不同水生植物类 型的变化 ${ }^{[18]}$. 因此各类附生硅藻的衰退表明水生植被类型的变化, 原有的水生植被群落发生改变, 生物多 样性减少. 其中, 在长江洪泛平原地区, A. minutissima 适宜在 TP 浓度为 $57 \mu \mathrm{g} / \mathrm{L}$ 左右的环境下生长 ${ }^{[27]}$. 此 属种成为优势种时, 表明水体 TP 浓度仍然较低, 尚未发生富营养化. 事实上, 水生植物的生长对营养和光具 有竞争优势, 可有效地减少沉积物中磷的再释放; 同时, 水生植物的发育使得水体抗风浪能力增强, 又可以 抑制磷的再悬浮作用, 使沉积物磷不参与再循环 ${ }^{[13]}$, 因此水体 TP 浓度始终低于 $55 \mu \mathrm{g} / \mathrm{L}$, 这表明草型湖对 输人的高浓度营养盐具有较强的缓冲作用. 因此, 本阶段虽然营养蓄积速率明显加快, 该湖营养水平持续上 升,但水体处于中营养水平, 尚未发生富营养化.

\section{2 梁子湖生态环境演化的驱动因素分析}

营养的输人对梁子湖生态环境演化起关键性作用. 圥余分析结果显示营养指标 TP 是最显著的因子, 其 独立解释了硅藻组合变化的 $12.7 \%$, 是影响硅藻组合演替的最主要因素. 沉积物营养指标(如 TP、TN、TOC 等) 含量高低与营养盐输人直接相关 ${ }^{[33-34]}$, 其含量增多往往指示湖泊营养富集. 然而, 在草型湖泊中, 营养盐 的输人首先为水生植被的发育提供了条件, 而水生植被的发育反过来对营养物质起到了拦截、吸附和快速 沉降的作用, 降低可利用性营养盐浓度, 一定程度上减轻水体营养水平, 这是一种负反馈调节作用. 因此, 随 着流域人类活动的增强, 虽然引起流域土壤侵蚀速率加快和人湖营养盐增多, 但由于水生植物的大量生长, 水体尚未发生富营养化. 值得注意的是, 在浅水湖泊中, 当营养态处于一定的过渡范围时, 湖水既能在藻类 增殖下变浑浊, 又能在丰富的水生植被发育下变清洁 ${ }^{[35]}$. 在营养盐浓度达到与草型 (藻型) 生态系统相适应 的浓度阈值情况下, 如果突然出现外部扰动 (如风浪、高水位、鱼等), 生态系统就会出现转化. 但是, 如果营 养盐浓度尚未达到这一阈值, 即使受外部扰动发生变化, 一旦这种扰动消失后, 原来的生态系统仍然可能会 恢复, 即生态系统的反弹 ${ }^{[36]}$. 据资料显示, 目前梁子湖营养状态已从贫营养型进人中营养型, 局部已接近富 营养型, 主要是氮、磷超标 ${ }^{[19]}$. 不仅如此, 1990s 以来沉积速率、TP 与 LOI 含量的显著增加也指示了流域营养 蓄积速率与输人量的明显增加. 因此,为避免水环境继续恶化, 必须控制流域内不当的人类活动.

重金属污染 (以元素 $\mathrm{Cu}$ 为代表) 对梁子湖生态环境有显著影响,其单独解释了硅藻组合变化的 $8.5 \%$. 重金属可以通过岩石淋溶、大气沉降、工业废水、地表径流等多种途径进人水体环境, 是水生生态系统中具 有稳固持久性的污染物质之一 ${ }^{[37]}$. 沉积物重金属元素能够反映自然与人类活动对湖泊的影响 ${ }^{[38]}$, 在工业化 之前主要来自流域基岩和表土的侵蚀输人,而近代以来重金属元素含量增多往往与流域工业化进程紧密相 关 ${ }^{[39-40]} .1958$ 年后, $\mathrm{Cu}$ 含量快速升高反映流域工业快速发展导致大量的工业废水排放人湖,使水体富营养 化和重金属污染, 从而导致水质恶化. 这与梁子湖周围的武汉等地区 1958 年以来以武汉钢铁公司的投产为 代表的现代工业大发展阶段有关 ${ }^{[41]}$. 据调查研究结果显示, 梁子湖重金属 $\mathrm{Cu}$ 的浓度已超过我国 1 级地表水 水质标准,梁子湖逐步呈现重金属污染的趋势 ${ }^{[37]}$.

通常, 湖泊水文要素 (水动力强度及水位等) 对浅水湖泊生态系统有着至关重要的影响 ${ }^{[8,30]}$, 但在梁子湖, 水文要素对湖泊系统的影响相对有限. 尽管硅藻群落在湖泊建闸前后所导致的湖泊水扰动减弱、极端的洪水 事件体现出了灵敏的响应 (如属种 A. granulata 的变化, 如上文所述), 但统计结果表明过去近百年来水文因素 并不是主要的影响因素, 整个湖泊生态系统(特别是水生植物群落) 并未受到水文驱动. 导致这种现象发生的 主要原因可能是: 梁子湖面积大, 水较深 (大部分区域> $4 \mathrm{~m}$ ), 且长期维持低-中营养状况. 在此种环境背景下, 加之相对丰富的水生植被, 水体相对清澈, 短暂的洪水事件或较小的水位变化本质上不影响生态系统的整体 
结构及功能. 换言之, 梁子湖的自身具有较强的抗扰动性, 恢复力较强. 相对于水文, 营养、污染要素变率变幅 大, 且强度持续增加, 因此环境效应更为明显. 当然, 本研究仅采用了流域洪涝灾害的半定量记录, 一定程度上 不能有效反映湖泊水文的真实状况,因此,对梁子湖生态系统的水文响应特征需开展更多的研究.

\section{3 对湖泊治理的启示}

该研究为长江中下游浅水湖泊的富营养化治理提供了重要信息. 首先, 梁子湖近百年来环境演化过程 与相对稳定的水体 TP 重建值表明草型湖对高输人的营养盐具有较强的缓冲作用. 因此, 这种 TP 浓度仍然 较低的草型湖泊可以作为该区富营养化藻型湖泊治理潜在的基准湖泊. 其次, 人类活动引起的营养输人是 调控该湖生态环境的主导因子. 对于草型湖泊, 营养的输人首先为水生植被的发育提供了条件, 而水生植被 的发育反过来对营养物质起到拦截、吸附和快速沉降的作用, 降低可利用性营养盐浓度, 一定程度上减轻水 体营养水平. 但如果营养盐浓度达到某一阈值情况下, 草型生态系统会变的非常不稳定, 其他外部条件的变 化都有可能导致草型生态系统崩溃而转向藻型生态系统. 因此, 为避免水环境继续恶化, 必须控制流域内不 当的人类活动. 最后, 重金属污染也是影响梁子湖生态环境演变的重要因素. 重金属具有难降解、生物富集 以及放大作用, 且随着水文条件变化和人类活动干扰存在重新释放到水体 “二次污染” 的风险 ${ }^{[37]}$. 因此, 湖 泊管理者必须理性地评估当前的治理手段,并适当地调整治理方法.

\section{5 结论}

1) 梁子湖沉积柱高分辨率的多指标分析 (硅藻、地球化学指标和粒度) 揭示了近百年来梁子湖生态环境 演变过程. 结果显示: 1960s 以前该湖水体环境优良, 基本呈现出良性循环的相对稳定的生态体系; 1960s 以 后, 随着人类活动的逐渐加强, 人湖营养盐逐渐增多, 但由于草型湖对高输人的营养盐具有较强的缓冲作 用,水体尚未发生富营养化.

2) 近百年来人类活动引起的营养输人是调控湖泊生态环境的主导因子, 而重金属污染也是影响该湖生 态环境的一个重要因素.

3) 本研究证实了草型湖泊具有较强的环境缓冲作用的事实, 因此梁子湖可以作为该区富营养化藻型湖 泊治理的基准湖泊.

\section{6 参考文献}

[1] 秦伯强, 高 光, 胡维平等. 浅水湖泊生态系统恢复的理论与实践思考. 湖泊科学, 2005, 17 (1): 9-16. DOI 10. $18307 / 2005.0102$.

[2] 杨桂山, 马荣华, 张 路等. 中国湖泊现状及面临的重大问题与保护策略. 湖泊科学, 2010, 22(6) : 799-810. DOI 10. $18307 / 2010.0601$.

[ 3 ] 常锋毅. 浅水湖泊生态系统的草-藻型稳态特征与稳态转换研究 [ 学位论文]. 武汉: 中国科学院水生生物研究 所, 2009.

[ 4 ] Yang XD, Anderson NJ, Dong XH et al. Surface sediment diatom assemblages and epilimnetic total phosphorus in large, shallow lakes of the Yangtze floodplain: their relationships and implications for assessing long-term eutrophication. Freshwater Biology, 2008, 53(7): 1273-1290.

[ 5 ] Smol JP, Stoermer EF. The diatoms: applications for the environmental and earth sciences. Cambridge: Cambridge University Press, 2010.

[ 6 ] 董旭辉, 羊向东, 刘恩峰等. 湖北太白湖 400 多年来沉积硅藻记录及湖水总磷的定量重建. 湖泊科学, 2006, 18 (6) : 597-604. DOI 10. 18307/2006. 0607.

[ 7 ] 陈 旭, 羊向东, 刘 倩等. 巢湖近代沉积硅藻种群变化与富营养化过程重建. 湖泊科学, 2010, 22 (4): 607-615. DOI 10. $18307 / 2010.0419$.

[8] 陈 旭, 羊向东, 董旭辉等. 近 50 年来环境变化对巢湖硅藻组合演替的影响. 湖泊科学, 2011, 23(5): 665-672. DOI 10. 18307/2011. 0501.

[ 9 ] Birks HB. Numerical tools in palaeolimnology: Progress, potentialities and problems. Journal of Paleolimnology, 1998, 20: $307-332$.

[10] Ter Braak CJF, Smilauer P. CANOCO Reference Manual and CanoDraw for Windows User's Guide: Software for Canonical 
Community Ordination (version 4. 5). Ithaca, N.Y. Microcomputer Power, 2002.

[11] Borcard D. Partialling out the spatial component of ecological variation. Ecology, 1992, 73(3) : 1045-1055.

[12] Hall R,Smol JP. Diatom as indicators of lake eutrophication. In: Eugene F ed. The Diatom: Application for the environmental and earth science. London: Cambridge University Press, 1999: 128-168.

[13] 董旭辉, 羊向东, 刘恩峰等. 圥余分析 (RDA) 在简化湖泊沉积指标体系中的应用一一太白湖为例. 地理研究, $2007,26(3): 477-484$.

[14] 顾延生, 邱海鸥, 谢树成等. 湖北梁子湖近代沉积记录对人类活动的响应. 地球科学: 中国地质大学学报, 2008 , $33(5)$ : 679-686.

[15] 熊汉锋, 谭启玲, 王运华. 梁子湖沉积物中氮磷分布特征研究. 华中农业大学学报, 2008, 27(2): 235-238.

[16] 盛继超, 刘建华, 祁士华. 梁子湖近代沉积物重金属含量研究初探. 安全与环境工程, 2004, 11(4): 9-13.

[17] 金 芳, 黄俊华, 汤新燕等. 梁子湖沉积物有机质碳同位素特征及其古气候指示意义. 地质科技情报, 2007,26 (3) : 13-18.

[18] 张清慧, 董旭辉, 姚 敏等. 沉积硅藻揭示的历史时期水生植被信息一以梁子湖为例. 水生生物学报, 2014,38 (6) : 1024-1032.

[19］李兆华, 孙大钟. 梁子湖生态环境保护研究. 北京: 科学出版社, 2009.

[20］王苏民，窦鸿身. 中国湖泊志. 北京: 科学出版社，1998.

[21] 刘子亭, 余俊清, 张保华等. 烧失量分析在湖泊沉积与环境变化研究中的应用. 盐湖研究, 2006, 14(2): 67-72.

[22] Liu EF. Environmental response to climate and human impact during the last 400 years in Taibai Lake catchment, middle reach of Yangtze River, China. Science of the Total Environment, 2007, 385(1/2/3) : 196-207.

[23] Krammer K, Lange-Bertalot H. Baeillariophyceae ( 1-4 Teil). In : Ettl H , Gerloff J, Heynig H et al eds. Susswasserflora von Mitteleuropa. Stuttgart and Jena : Gustav Fischer Verlag , 1986-1991.

[24] 丁有国，姜 斌. 鄂州市志. 北京: 中华书局, 2000: 1-1018.

[25] 郑祚芳, 祁 文, 张秀丽. 武汉市近百年气温变化特征. 气象, 2002, 28(7): 18-21.

[26] 张秀丽, 郑祚芳. 近百年武汉市主汛期降水特征分析. 气象科学, 2002, 22(4): 379-386.

[27] 董旭辉, 羊向东, 王 荣等. 长江中下游地区湖泊硅藻一总磷转换函数. 湖泊科学, 2006, 18 ( 1): 1-12. DOI 10. $18307 / 2006.0101$.

[28] Tadonlk RD. Evidence of warming effects on phytoplankton productivity rates and their dependence on eutrophication status. Limnology and Oceanography, 2010, 55(3) : 973-982.

[29] Karst TL, Smol JP. Paleolimnological evidence of limnetic nutrient concentration equilibrium in a shallow, macrophytedominated lake. Aquatic Sciences, 2000, 62(1) : 20-38.

[30] 陈修康, 郭跃华, 冯 喻等. 特大洪水对浮游植物群落及其演替的影响一以广东高州水库为例. 湖泊科学, 2014, 26(1) : 137-146. DOI 10. 18307/2014. 0117.

[31] 《武昌县志》编纂委员会. 武昌县志. 武汉: 武汉大学出版社, 1989: 1-688.

[32] 史小丽, 秦伯强. 长江中游网湖近代沉积环境演变及其对人类活动的响应. 地理研究, 2013, 32(5): 808-816.

[33] Wu Y, Lücke A, Wang S. Assessment of nutrient sources and paleoproductivity during the past century in Longgan Lake, middle reaches of the Yangtze River, China. Journal of Paleolimnology, 2008, 39(4) : 451-462.

[34] 姚书春, 李世杰. 巢湖富营养化过程的沉积记录. 沉积学报, 2004, 22(2): 343-347.

[35] 秦伯强，杨柳燕，陈非洲等. 湖泊富营养化发生机制与控制技术及其应用. 科学通报，2006，51(16)：1857-1866.

[36] 秦伯强, 宋玉芝, 高 光. 附着生物在浅水富营养化湖泊藻-草型生态系统转化过程中的作用. 中国科学: C 辑: 生 命科学, 2006, 36(3): 283-288.

[37] 刘 晖, 张 昭, 李 伟. 梁子湖水体和底泥中微量元素及重金属的空间分布格局及污染评价. 长江流域资源与 环境, 2011, (S1) : 105-111.

[38] 袁旭音, 王爱华, 许乃政. 太湖沉积物中重金属的地球化学形态及特征分析. 地球化学, 2004, 33(6): 611-618.

[39] Shen J, Liu E, Zhu Y et al. Distribution and chemical fractionation of heavy metalsin recent sediments from Lake Taihu, China. Hydrobiologia, 2007, 581:141-150.

[40] Wu Y, Liu E, Yao S et al. Recent heavy metal accumulation in Dongjiu and Xijiu lakes, East China. Journal of Paleolimnology, 2010, 43(2): 385-392.

[41] 孙毓棠. 中国近代工业史资料(1840-1895 年). 北京: 科学出版社, 1957. 